\title{
BMJ Open Conceptualising cultural safety at an Indigenous-focused midwifery practice in Toronto, Canada: qualitative interviews with Indigenous and non- Indigenous clients
}

Mackenzie E Churchill (D) , ${ }^{1}$ Janet K Smylie, ${ }^{1,2}$ Sara H Wolfe, ${ }^{3}$ Cheryllee Bourgeois, ${ }^{3}$ Helle Moeller, ${ }^{4}$ Michelle Firestone ${ }^{5}$

To cite: Churchill ME, Smylie JK, Wolfe SH, et al. Conceptualising cultural safety at an Indigenous-focused midwifery practice in Toronto, Canada: qualitative interviews with Indigenous and nonIndigenous clients. BMJ Open 2020;10:e038168. doi:10.1136/ bmjopen-2020-038168

- Prepublication history for this paper is available online. To view these files, please visit the journal online (http://dx.doi. org/10.1136/bmjopen-2020038168).

MEC, JKS and SHW contributed equally.

MEC, JKS and SHW are joint first authors.

Received 04 March 2020 Revised 30 June 2020 Accepted 13 August 2020

A) Check for updates

(C) Author(s) (or their employer(s)) 2020. Re-use permitted under CC BY-NC. No commercial re-use. See rights and permissions. Published by BMJ.

For numbered affiliations see end of article.

Correspondence to Mackenzie E Churchill; mackenzie.churchill@gmail.com

\section{ABSTRACT}

Objective Cultural safety is an Indigenous concept that can improve how healthcare services are delivered to both Indigenous and non-Indigenous peoples in Canada. This study explored how Indigenous and non-Indigenous clients at an urban, Indigenous-focused midwifery practice in Toronto, Canada (Seventh Generation Midwives Toronto, SGMT) conceptualised and experienced culturally safe care.

Design and setting Interviews were conducted with former clients of SGMT as a part of a larger evaluation of the practice. Participants were purposefully recruited. Interviews were transcribed and analysed thematically using an iterative, consensus-based approach and a critical, naturalistic, and decolonising lens.

Participants Saturation was reached after 20 interviews ( $n=9$ Indigenous participants, $n=11$ non-Indigenous participants).

Results Three domains of cultural safety emerged. Each domain included several themes: Relationships and Communication (respect and support for choices; personalised and continuous relationships with midwives; and being different from past experiences); Sharing Knowledge and Practice (feeling informed about the basics of pregnancy, birth, and the postpartum period; and having access to Indigenous knowledge and protocols), and Culturally Safe Spaces (feeling at home in practice; and having relationships interconnected with the physical space). While some ideas were shared across groups, the distinctions between the Indigenous and non-Indigenous participants were prominent.

Conclusion The Indigenous participants conceptualised cultural safety in ways that highlight the survival and resurgence of Indigenous values, understandings, and approaches in cities like Toronto, and affirm the need for Indigenous midwives. The non-Indigenous participants conceptualised cultural safety with both congruence, illuminating Black-Indigenous community solidarities in cultural safety, and divergence, demonstrating the potential of Indigenous spaces and Indigenous-focused midwifery care to also benefit midwifery clients of white European descent. We hope that the positive impacts documented here motivate evaluators and healthcare
Strengths and limitations of this study

- To the best of our knowledge, this study is one of the few to evaluate cultural safety from the perspective of clients-the only people who can truly define whether a health service is culturally safe.

- Qualitative interviews offered a glimpse into the unique ways in which Indigenous and nonIndigenous clients of an urban Indigenous-focused midwifery practice in Canada conceptualised and experienced culturally safe care.

- Participants tended to be older, more educated, and have more hospital births than the average client at the practice; there were also no Inuit-identified participants among the Indigenous participants, and the majority of non-Indigenous participants were white/ European.

- Focusing on a single midwifery practice, care must taken in interpreting the study's relevance across pregnancy, birth, and postpartum settings and communities.

providers to work towards a future where 'cultural safety' becomes a standard of care.

\section{INTRODUCTION}

\section{Background}

Given the context of historical and ongoing settler colonialism, anti-Indigenous racism has been embedded in the Canadian healthcare system since its inception. ${ }^{1}$ Resulting harms to First Nations, ${ }^{2}{ }^{3}$ Inuit, ${ }^{4}$ and Métis peoples $^{5}$ have been well documented. ${ }^{6}$ One of the most disturbing examples is the death of Brian Sinclair, a Cree man who died from complications of a treatable urinary tract infection in a Winnipeg emergency room in 2008 after waiting for 34 hours without being triaged. ${ }^{7}$ Unfortunately, Sinclair's story is not unique. Indigenous peoples are frequently 
ignored, shamed, and/or belittled by healthcare staff; misdiagnosed based on stereotypes; made to wait for long periods of time for services without explanation; denied healthcare services; and threatened with or face unfounded calls to child protection agencies across the spectrum of perinatal, infant, child, youth, adult, and senior care. ${ }^{2-689}$ As a result, many Indigenous peoples avoid healthcare services until they are critically necessary, or refuse care altogether. ${ }^{689}$ Black patients have reported similar harms in healthcare rooted in systemic anti-Black racism. ${ }^{10} 11$

Several approaches have been proposed to improve how Indigenous and racialised peoples are treated in the healthcare system. Common approaches include improving the 'cultural awareness', 'cultural sensitivity' and/or 'cultural competency' of healthcare providers. Although popular, these approaches have been criticised for building on narrow understandings of culture that promote stereotyping, reduce human interactions to check lists, normalise the 'Othering' of racialised communities, and obscure the influence that structural forces have on health and well-being. ${ }^{12-17}$ These approaches have also failed to redress inequalities in health outcomes that are rooted in systems of oppression, such as racism, sexism and settler colonialism. ${ }^{12}$

\section{Cultural safety}

'Cultural safety' is a concept that was first developed by Indigenous (Māori) nurses in New Zealand to improve how services were being delivered to Māori patients. ${ }^{13}$ Cultural safety is distinct from previous approaches for several reasons. First, it is built on the understanding that 'culture' is not static nor superficial. Rather, it is fluid, dynamic, complex, and sociopolitical - culture is integral to social structuring, knowledge systems, and relationships. $^{1317}$

Second, cultural safety is both a process and an outcome. Cultural safety therefore encompasses the planning, delivery, evaluation, and outcomes of health care services. ${ }^{12}{ }^{18}$ Whereas culturally unsafe care includes 'any actions [or omissions] that demean, diminish or disempower the cultural identity and well-being of the individual ${ }^{19}$ (p.5) and is enabled by systems of oppression, culturally safe care is the process and outcome of feeling comfortable, respected, and safe in one's cultural identity.

Finally, and most importantly, cultural safety dictates that the only person who can truly define whether a service is culturally safe is the person receiving that service. ${ }^{13}$ By centering client feedback, cultural safety attends to and challenges client-provider power imbalances that give few opportunities for client experiences to drive change. Service providers, meanwhile, are required to engage in a lifelong process of critical self-reflection, learning, and growth related to their sociopolitical identities and locations. ${ }^{12}$ Confronting the realities of how settler colonialism and racism have impacted and continue to impact the services they and others provide is a critical first step to this process.
Although cultural safety has gained interest and uptake across Canada, ${ }^{20}{ }^{21}$ little has been published with regards to how best to assess, evaluate, and build accountability for cultural safety in healthcare, social services, and education. There is also room to explore what cultural safety means for non-Indigenous peoples. ${ }^{22} 23$

\section{Indigenous and non-Indigenous midwifery in Canada}

In what is now known as Canada, Indigenous midwives are leaders in delivering culturally safe care. Cultural safety - or the creation and protection of the sacred space in which each person, in their uniqueness, can feel safe to express who they are and what they need ${ }^{24}$ (p.3) - is a core value of the National Aboriginal Council of Midwives (NACM). Even though Indigenous midwives have been supporting families and communities since time immemorial, it was only recently that Indigenous and non-Indigenous midwives re-entered the perinatal mainstream in Canada due to generations of attempted erasure, suppression, and delegitimatisation. ${ }^{25}$

In 1994, Ontario became the first province to regulate midwifery. ${ }^{25}$ Registered Midwives in Ontario are primary care providers who offer comprehensive services to people during pregnancy, birth, and up to 6 weeks postpartum. ${ }^{26}$ Midwives typically support clients with low-risk pregnancies, and work from the philosophies of choice of birthplace (ie, home, hospital, and/or birth centre), informed choice, and continuity of care. ${ }^{27}$ Respect for client dignity, autonomy, cultural safety, and experience as central to decision making are listed among the values of the Association of Ontario Midwives. ${ }^{28}$

Indigenous midwives in Ontario are practitioners who self-identify as Indigenous, and practice as either Registered Midwives or Aboriginal Midwives working under theExemption Clause. ${ }^{25}$ Indigenous midwives are unique because they bring a specific approach, knowledge base, set of skills, and core competencies that enable them to support parents and families during the birth year and early life in a culturally safe way. ${ }^{24}$

The literature exploring Indigenous midwifery, and culturally safe perinatal care in general, is still emerging. The majority of studies are from Australia and evaluate cultural safety from the perspectives of care providers, rather than recipients. ${ }^{29-31}$ There is also a gap in the cultural safety literature with regards to place, as most studies focus on rural, remote, and/or northern communities. ${ }^{32}{ }^{33}$ Considering that the majority of Indigenous peoples in Canada now live in urban centres, and that anti-Indigenous racism persists, there is an urgent need to understand what culturally safe care looks like in urban settings to ensure the provision of quality services and interrupt ongoing harms.

Seventh Generation Midwives Toronto (SGMT) is an Indigenous-focused midwifery practice in Toronto, Canada that strives to meet this need. ${ }^{34}$ Toronto is one of the largest and most ethnically diverse cities in Canada. ${ }^{35}$ It has the largest population of Indigenous people in Ontario, with recently confirmed estimates of at least 
70000 people. ${ }^{36}$ Accordingly, SGMT welcomes both Indigenous and non-Indigenous clients into their practice, and has Indigenous and non-Indigenous midwives on staff. As an Indigenous-focused practice, SGMT reserves spaces for Indigenous clients with low-risk and high-risk pregnancies; trains student-midwives and is designated as a priority placement for Indigenous students; creates opportunities for Indigenous clients to include Indigenous teachings, practices, and protocols in their care; and supports all families to reflect on the importance of culture and tradition in their birth year experience.

SGMT initiated its first practice evaluation in 2014. In this qualitative study, we present findings from interviews with clients that were conducted as a part of this evaluation. The purpose of this study was to determine how Indigenous and non-Indigenous clients at SGMT conceptualised cultural safety, and the extent to which their experiences at SGMT aligned with these conceptualisations.

While we use the collective terms 'Indigenous' throughout this article, the diversity and richness of First Nations, Inuit, and Métis cultural heritage and expression as Indigenous peoples from many nations and backgrounds coming together in a large urban centre should not be underestimated. Support for self-determined and relationship-based cultural expression, cultural respect, and sharing across these diversities is a core premise of SGMT's practice, ${ }^{37}$ and cultural safety in Toronto more generally.

\section{METHODS}

\section{Study overview and approach}

This study was initiated as a part of a multi-phased Indigenous health service evaluation of SGMT that was informed by informed by Indigenous, utilisation-focused, and realist methodologies. ${ }^{38-40}$ The aim of the evaluation was to learn how, why, and for whom SGMT works and to develop a culturally relevant performance measurement system for the practice. Evaluation questions included: (1) What are the maternal, child, and family birth outcomes for SGMT clients? (2) What are the key prenatal, birthing, and reproductive health needs of our clients and how are we meeting these needs? (3) How do our clients define culturally secure reproductive healthcare? And (4) Is SGMT contributing to changes in attitudes and behaviours regarding Indigenous peoples, knowledge, and practice, and how? The evaluation consisted of: (A) key informant interviews with SGMT clients and SGMT midwives, (B) precare and postcare questionnaires for SGMT clients, and (C) SGMT outcome legacy data from 2005 to 2012. This study reports on findings from the key informant interviews with SGMT clients.

The SGMT evaluation was co-led by Indigenous midwives at SGMT (SHW and CB) in partnership with researchers at the Well Living House based at St. Michael's Hospital in Toronto (JKS and MF). This evaluation built on over ten years of pre-existing Indigenous community, clinical, and research collaboration between the community and academic leads (SHW, CB, and JKS).

The evaluation design and implementation drew on the Well Living House's established methods and protocols for conducting rigorous, ethical, and high-quality Indigenous health research ${ }^{41-44}$ and published best practices. ${ }^{45}$ These methods balance tangible community benefits with research excellence, strong and reciprocal relationships, capacity building, Indigenous leadership, and Indigenous governance and management of Indigenous information. ${ }^{46}$ The roles and responsibilities of the evaluation partners (ie, the Well Living House and SGMT) with study conduct, governance, data sharing, and SGMT data ownership were delineated in a project-specific data sharing, research, and publication agreement. The midwives were actively involved in the evaluation, co-leading the development of the evaluation questions, logic model, and evaluation tools (eg, interview guide used for this study). The midwives were also involved in the training of data collectors, recruitment of participants for the interviews and questionnaires, and the vetting of evaluation outputs.

\section{Participant recruitment and data collection}

Potential participants were identified using purposeful sampling ${ }^{47}$ to best represent the diversity of needs, choices, and healthcare experiences observed at SGMT. SGMT midwives compiled a list of clients who were $\geq 18$ years old, gave birth in 2014, and represented different social locations-including age, family structure, socioeconomic status, education level, Indigenous/nonIndigenous identity, race, and birth outcomes-to be potential participants.

The SGMT receptionist made first contact with potential participants. Potential participants who expressed interest in the study and gave permission to be contacted were telephoned by MEC. MEC is a white settler cisgender woman who at the time of the study was a novice researcher completing her Master of Public Health. She had no previous relationship with SGMT, midwifery, childbirth, or the participants. MEC received training and mentorship from the SGMT midwives and WLH researchers to prepare for participant contact and interviewing. Mentorship included conducting practice interviews with past Indigenous client volunteers and receiving direct critical feedback from an Indigenous midwife on relational approaches to interviewing.

During the initial phone call, MEC explained the study, answered questions, and if appropriate, scheduled an in-person meeting with the potential participant. During the subsequent meeting, MEC reviewed the study in depth, assured them that their participation or lack thereof would have no impact on their future care with SGMT, answered questions, and obtained informed consent. All interviews were conducted in-person by MEC between October 2014 and March 2015. Interviews varied in length from 20 min to 1 hour and took place in quiet, private locations of the participants' choice (eg, coffee 
shops, homes, SGMT office). The interviews were digitally recorded with participant consent. One participant requested that their interview be transcribed via laptop. Participants were asked whether they wished to review their transcripts prior to analysis to enhance the accuracy, validity, and credibility of the study, ${ }^{48}$ and four requested this review. Participants were given a small gift and monetary compensation (US\$20) to acknowledge their contributions and cover any costs related to participation.

Questions focused on past experiences with perinatal care; specific needs during pregnancy, birth and the postpartum period; experiences receiving care from SGMT; culturally safe care; and the role(s)/importance of identity and knowledge sharing. Cultural safety was explained to participants as 'what makes you feel comfortable, respected and able to be yourself'. The interview guide is presented in online supplemental appendix A. The research team members from SGMT (SHW and CB) and Well Living House (JKS and MEC) agreed that saturation had been reached after 9 Indigenous participant interviews and 11 non-Indigenous participant interviews $(n=20)$, as no new themes or ideas were emerging. ${ }^{49}$

\section{Data analysis}

The recordings were transcribed verbatim by MEC and verified by a second Well Living House researcher. Transcripts were analysed thematically using an established consensus-based, iterative method that involved both academic and community-situated peer researchers and applied a critical, naturalistic, and decolonising interpretive lens. ${ }^{43}$ This lens is based on key assumptions that have been detailed elsewhere ${ }^{41}$ (p.437-438). The aim of our methodological approach was to centre Indigenous perspectives and to understand and represent the gathered information in a way that was as true to the lived experiences of the Indigenous and non-Indigenous participants as possible.

Analysis began with a mixed academic-community team completing an in-depth review and preliminary themebased coding of the transcripts. The team consisted of MEC, a white settler researcher who at the time was completing a Master of Public Health; JKS, a wellknown Métis family physician and applied public health researcher; and a third reviewer, a First Nations woman who was invited to independently contribute based on her lived experience as a former SGMT client and experience in qualitative analysis. Each team member was tasked with individually identifying the major themes in the transcript along with key quotations that illustrated this them. After this preliminary independent thematic coding, the team met to reach consensus on major themes and develop a codebook with exemplar quotations. MEC then conducted an in-depth analysis of the transcripts using a crystallisation-immersion process ${ }^{50}$ to further develop the coding. The resultant analysis was iteratively refined in a series of meetings among the three reviewers, and then presented to community research partners SHW and CB for final review and approval.

\section{Patient and public involvement}

An advantage of our Indigenous community-partnered research approach and Indigenous leadership of both the academic and community research team is that 'patient and public involvement' are built into the research process. Collectively, the three Indigenous authors (JKS, SHW and CB) have more than 65 years of experience providing Indigenous-focused maternity care and they have all also personally experienced Indigenous midwifery care. Further, the larger evaluation of SGMT was informed by a number of focus groups that involved Indigenous Elders, Indigenous community members, and SGMT midwives. Indigenous experiences, priorities, and preferences of clients were, therefore, central throughout the evaluation, including the development of research questions, outcome measures, study design, and recruitment of participants. This specific study, in addition to being focused on client informants, included former SGMT clients for community context in the data analysis to ensure the results would be as true to the lived experiences of community members as possible. These aspects included data collection (ie, participant interviews) and analysis (ie, opportunities for member checking and inclusion of the independent research analyst who was a former client of SGMT). Results from this study will be shared at conferences, in publications, and/or in community-friendly fact sheets distributed to SGMT clientele and study participants. Because SGMT owns the data, all materials must be reviewed and approved by SGMT before distributing.

\section{RESULTS}

Three domains of cultural safety emerged from the analysis: (1) Relationships and Communication, (2) Sharing Knowledge and Practice, and (3) Culturally Safe Spaces. Several themes were identified in each domain. The themes are presented below, supported by quotes from the Indigenous and non-Indigenous participants. The Indigenous/ethnic identity of each quoted participant is coded following each quotation below using 'I' for Indigenous and ' $\mathrm{N}$ ' for non-Indigenous, followed by a participant number and specific ancestry/ethnicity. The demographic information of participants is presented in table 1 .

\section{Relationships and Communication \\ Respect and support for choices}

When describing cultural safety, many participants $(n=13)$ emphasised the importance of feeling respected and supported in their choices:

Culturally appropriate care would be something that is respectful of any practices that I would have that I would want to do, not judgmental about choices that I'm making, giving me informed or information about a choice I made that they may not necessarily 
Table 1 Demographic characteristics of participants $(n=20)$

\begin{tabular}{|c|c|c|}
\hline Characteristic & $\begin{array}{l}\text { Indigenous } \\
\text { participants }\end{array}$ & $\begin{array}{l}\text { Non-Indigenous } \\
\text { participants }\end{array}$ \\
\hline Age (avg) & 33.8 & 34.5 \\
\hline \multicolumn{3}{|l|}{ Education } \\
\hline High school & 2 & 0 \\
\hline College & 2 & 1 \\
\hline University & 3 & 5 \\
\hline $\begin{array}{l}\text { Graduate/ } \\
\text { professional }\end{array}$ & 2 & 5 \\
\hline \multicolumn{3}{|l|}{ Parity } \\
\hline Primiparous & 4 & 8 \\
\hline Multiparous & 5 & 4 \\
\hline \multicolumn{3}{|l|}{ Birth place } \\
\hline Birth centre & 1 & 1 \\
\hline Hospital & 8 & 7 \\
\hline Home & 0 & 3 \\
\hline $\begin{array}{l}\text { Indigenous/ } \\
\text { ethnic identity* }\end{array}$ & $\begin{array}{l}\text { First Nations: } 7 \\
\text { Métis: } 2 \\
\text { Inuit: } 0\end{array}$ & $\begin{array}{l}\text { European/white: } 7 \\
\text { Racialised: } 4\end{array}$ \\
\hline
\end{tabular}

*Loosely based on participant self-identification.

follow their model of care ... but respecting my choices regardless. (I5, Métis)

'Choice' was broadly defined to include life choices, choices about pregnancy and birthing, and choices about client involvement in decision making. Respect and support for choices, then, was made possible when the midwives withheld judgement, honoured the participant's decisions, and/or advocated on their client's behalf:

When I first met [my primary midwife], I was feeling insecure and she made me feel really confident, like what I was doing, you know, choosing to be a single mom. She really helped me feel like it was a good choice instead of something to be afraid of. (N13, white/European)

[My midwife was] warm, easy to talk to, she didn't judge me for anything I said. She just... she understood, you know. She didn't, like even though, yes, she had to remind me 'it's better to breastfeed,' she never pushed the idea on me, you know what I mean? (I4, First Nations)

[My midwife] was able to like be in my corner and be like 'no, she doesn't actually have to do this. ... There's nothing indicating that she needs to be in this position'. So because of that, she kind of gave me the strength to continue to be my own advocate even when she wasn't in the [hospital] room. (I7, First Nations)
One participant felt that her midwives could have been more supportive of their preference for a midwife-led approach:

Just saying, 'you can do it or you don't have to do it,' to me, is not what I'm looking for. I still want to have the choice, but I'd like someone to explain the risks, the benefits, what most people do, why most people do what they do. (N11, white/European)

\section{Personalised, continuous relationships with midwives}

Cultural safety was also conceptualised as having personalised, continuous relationships with midwives. Participants from both groups described these relationships as being treated like a human and peer rather than a number, not feeling rushed, and receiving individualised emotional and mental health support.

You can feel when somebody actually cares, as opposed to making it a clinical situation. ... I mean sometimes we would just chit-chat and it was nice, you know? (N14, Caribbean and European)

Once I was in the room with the midwives... all the attention was on me. Just taking the time to ask any questions or, you know, not make me feel like I was being asked to get in and out as quickly as possible. ... I felt like I would be able to build a good relationship with the midwives there. (I8, Métis)

It was very important to have a little bit of the emotional support that just, kind of, buoys you when you're pregnant and feeling awful and overwhelmed. ... That's not something I have at home, so it was good to know that I had somebody to provide that, as well as that sort of physical and medical backup. (N19, white/European)

However, for most of the Indigenous participants and one of the racialised non-Indigenous participants, these relationships were more specifically conceptualised as two-way, kin-based relationships built on shared understandings and experiences.

I would like to imagine my childbirth experience to be, to feel like I'm amongst sisters and not with a medical professional. And with my sisters I know their story, and so I feel like I would like to know my midwives' story a little bit more.' ... I think that's important and it develops trust and well, really, a sense of community. (I1, First Nations)

It's nice when [the midwives] would share where they're from. [My midwife] said what reserve she's from ... and she shared her stories. It made me feel more comfortable in talking to her and sharing my story and going through the journey of giving birth, cuz it's a very personal, highly personal, thing. (I6, First Nations)

It was literally about bringing this new person into the world and welcoming her in this, kind of, almost like a sisterhood. (N20, Black/Caribbean) 
This was also evident when some of the Indigenous participants explained why it was so important to have an Indigenous-identified midwife.

The ideal is the Aboriginal midwife, just being Aboriginal herself. She understands what it means to be an Aboriginal woman because she's lived that life. ... She would know and understand and we'd have that connection. We'd understand each other. (I6, First Nations)

Throughout the pregnancy, the student was awesome because she was, for one, she was Aboriginal so she gets it. Secondly, she just had a calming effect on me. And so, I liked that. And she, she didn't make anybody feel lesser or higher than her. She was at the same level and that's what I loved about that. (I9, First Nations)

Only one Indigenous participant (IP8, Métis) felt that her non-Indigenous midwife "practiced culture care as much as my Aboriginal one ... She might have been more sensitive because she wasn't [Indigenous]'.

For some of the Indigenous participants, personalised and continuous relationships also meant the midwives facilitating the intergenerational transmission of knowledge and participation in care, and practising beyond the scope set by the Ontario midwifery model of care or standards of practice.

My daughter was there for my birth, so that was a big thing for me too. I was kind of hesitated about if she should come or if she couldn't come, but the midwives, were like, you know, 'it's fine, she can come. (I3, First Nations)

I think for my mom, who isn't in touch with her Aboriginal culture, I think it was really nice for her to live through it through me.... She came to one of my appointments with me and she made me a moss bag, so you know? Just really celebrating her culture where she felt safe to do it. (I8, Métis)

[When] I was at the children's hospital], my midwife actually gave me money to buy food because they don't feed people, they don't feed grown ups [there].

(I4, First Nations)

There are ceremonies that you have for couples too, right? Like in parenting. I would've loved to have learned a little bit about that kind of stuff [at the practice]. (I9, First Nations)

For the non-Indigenous participants, personalised relationships were described in more client-centred terms; several participants spoke to the importance of the midwives 'getting to know the patient and making sure that they're sort of doing everything they can to have a healthy pregnancy and maintain their own health emotionally and physically' (N16, white/European). Continuity of care was also understood as such, with participants identifying having the same midwife/group of midwives, being visited at home and receiving comprehensive post-partum care as vital to feeling supported, respected, and able to be themselves.

I think in terms of labour and delivery, I think having the actual person you developed a relationship with is hugely important. ... That made a huge difference, I think, in my comfort in that experience, "cause they know you, they know how to keep you calm, and yeah, you feel better. (N11, white/European)

To have somebody tell you, 'nope, everything's fine, everything's perfect, she's perfect; nope, she's progressing as she should be; no, this jaundice this nothing to worry about it's only a little bit.' All of those things, it's just constant reassurance and it just allows you to just focus on what you should be focusing on, which is a newborn, getting a bit of sleep, all that kind of stuff. (N12, white/European)

It was great because they could come to the house and I had [my first child], she's quite [laughs]... she's not a handful, but especially after you've just given birth, they would come to the house and check up on the baby and they... seemed to really take time with the baby too and she wasn't just a number, like they actually cared about how she was doing. (N10, white/ European)

\section{Being different from past negative experiences}

Fourteen participants, nine of whom were Indigenous and one of whom was non-Indigenous and racialised, drew on their past negative experiences with hospitalbased healthcare providers and systems to explain what cultural safety was not.

I have a background of having doctors not listen to me. Or not respect my opinion. And so there was a fear that if I had to make some decisions ... that my options weren't gonna be considered. ... So that's what I mean by [not wanting to be in a] medical setting where everything's standardized-your individual concerns aren't really heard. (I8, Métis)

I had a rather bad experience with the obstetrician we started with-like I didn't feel she was taking our concerns serious. ... [After I asked my] third question, she was like literally cutting me off, and she wasn't even sitting down for the appointment. She was just like standing in the doorway the whole time! So that's when I said to my [partner], 'we need to find midwifery care'! (N17, white/European)

\section{Sharing Knowledge and Practice}

Feeling informed about the basics about pregnancy, birth, and the postpartum period

All 20 participants valued the clinical information they received from their midwives, feeling supported and safe when they knew what to expect physiologically and what options were available.

Having [the midwives] talk to me, and really provide me with information so I can make an informed 
consent, an informed decision, and that would be where I felt respected. (I2, First Nations)

I needed information, mainly because it was my first pregnancy, so like everything is new. And as much as you read online, you need someone to guide you or answer your questions. So information was the main [support I needed], I would say. (N15, Middle Eastern)

I didn't know anything about pregnancy. I think the last time I was around anyone that was pregnant was my sister... [and] it's been awhile. Anything that came out of [the midwife's] mouth could help me! (I9, First Nations)

There was also some discussion about how information was being communicated, with participants emphasising the importance of using accessible language and welcoming families of all identities.

I was looking for, sort of the medical side of the pregnancy information to be delivered in a non-medical setting. That was very important to me. I didn't feel like it was a medical process to be pregnant, nor was childbirth a medical emergency.... The midwives' approach was informative, calm. All the information was delivered in such a consumable way for me, an understandable way for me. (NA19, white/European)

They do the home birth class and have a question and answer night just for dads. ... Let's change that language and make sure that it's accessible to all partners and not just male partners. I think that the other piece was just watching the language on some of their intake forms and paying attention to pronouns, and making it a little more accessible to the LGBTQ population, given that Two-Spirited is something that is part of the Aboriginal culture and it's not on any of their paperwork. (I5, Métis)

\section{Having access to Indigenous knowledge and protocols}

All of the Indigenous participants and three of the nonIndigenous participants conceptualised cultural safety as being able to access Indigenous knowledge, teachings, ceremony, and protocols ('Indigenous knowledge and protocols') during the perinatal period. For one Indigenous participant, cultural safety was about access and:

Treating cultural things as 'normal,' so it's not a novelty thing that like I was seeing a healer and he was giving me teas to drink. ... Like [the midwives] just took it at value that, like, a traditional person gave those to me. (I7, First Nations)

Indigenous knowledge and protocols did not only encompass more formal teachings, medicines, and ceremony, but also, everyday practices and protocols such as including family members, learning via storytelling, and sharing food and drink:

Something that would make me feel more culturally rooted would be the chance to either accept or offer food or drinks. Not just water, but like if there was, I don't know, like a tea station or something. Something that makes me feel like I'm going to my granny's house, you know? Or to my auntie's house, or you know? Like where you're just a cup of tea. (I1, First Nations)

Eight of the Indigenous participants sought care from SGMT to access Indigenous knowledge and protocols. All of the Indigenous participants who were given the opportunity to include Indigenous knowledge and protocols in their midwifery care reported benefits:

You know how long it takes for your chest to go down [after labour]? It took me two days with that tecta [tea], so it was very helpful. (I4, First Nations)

[My primary midwife] smudged with some tobacco that she got and that was quite sacred to her. So that was really special that we really got to smudge before her birth. ... It calmed me down because I wasn't ready for [my baby] to be born; she was too early. (I2, First Nations)

We could smudge when I was in labour, right? That was a big thing for me. Doing that meant a lot and especially giving my daughter a cedar bath when she was born, that meant a lot to me too, right? So it's impacted me a lot, my culture, in the last few years. And I'm happy to be giving my children that now because I understand it more and I know a little more about my culture, and now they can pass it on. (I3, First Nations)

Six Indigenous participants felt that there was room for their midwives to better initiate conversations about Indigenous knowledge and protocols. Some participants did not know what to ask for, or how to ask for it.

I remember that experience being told about the cedar bath ... I really have no clue how to do the ceremony. And so I think the assumption was, 'no, just do a cedar bath, you know? Put cedar in a bath.' So I think some things have to be spelled out so people feel comfortable doing it, cuz if it's not... you feel like you're misrepresenting the cultural practice and you're not passing it on properly. (I8, Métis)

My midwife just took it upon herself to say, 'hey do you wanna smudge?' and we're like 'yeah, that's great, like we didn't even know that was an option' because of, you know, you're in a hospital. ... She did it on her own and she asked me in the birthing room if it was something I wanted to do and... then she told me the story of the tobacco and how she got it and it was pretty special. So it made me feel quite, quite special about that. (I3, First Nations)

The importance of the midwives asking/inviting became clear after one Indigenous participant was not asked, which made the participant feel 'that I'm not Aboriginal, right? That I'm not Métis' (I5, Métis). She 
went on to share that she was hoping for 'an experience where I would learn a little bit more. My grandparents passed away when I was fairly young and we moved to a very white community, which sort of segregated any teachings that I would've experienced from them'. (I5, Métis)

All of the Indigenous participants wished that they had access to more Indigenous knowledge and protocols. Some Indigenous participants spoke to the challenges of this task, such as the impacts of colonial suppression:

In the community that I was brought up in, we haven't really shared childbirth, traditional knowledge about childbirth. And so it's not something that my sisters and I carry with us today that we can share amongst others. So if they have anything that they could share related to traditional knowledge and childbirth, I would love to hear about it because I feel like it's something that's been lost (I1, First Nations).

Three of the non-Indigenous participants were interested in accessing Indigenous knowledge and protocols at SGMT. Two of these participants had children whose biological fathers were Indigenous. One participant, who used an Indigenous sperm donor, felt that the cultural and spiritual aspects of her care 'didn't get as developed as I would have liked' (N13, white/European). Another participant, who had a previous relationship with her child's father, was offered a smudge during labour but ran out of time. She was grateful for the sage because 'it was like a little memento from the experience and everything and I think also, even though I'm not with [their] dad, that knowing that would've also gave him some level of peace ... 'cause he couldn't be here' (N20, Black/Caribbean). The third participant, after experiencing a perinatal loss, had her child honoured at a ceremony attended by her Indigenous midwife. She felt that this ceremony was key to her healing because afterwards, 'it was just like I knew that some of the things I'd been feeling subconsciously but couldn't quite vocalise had been met' (N17, white/ European).

\section{Culturally Safe Spaces}

Feeling 'at home' in practice

Cultural safety was also conceptualised as being in a physical space that made participants feel 'at home.' Even though most participants $(n=18)$ described this space as 'less clinical' and more 'homey,' the ideals fell on a continuum ranging from the Toronto Birth Centre to their own home settings.

I think the home environment would be my ideal place. ... I think the true privacy, that it really is your space. You know, no matter what you do to a hospital room or to a birthing centre room it never really becomes 'your' space, but this [home] is always going to be your space. And it's just, you know, you can labour in any position you want, there's no... medical equipment just hanging in the corners waiting for you. (I2, First Nations)
One of the non-Indigenous participants felt more at home in a 'more medicalised space' (N11, white/ European), whereas one of the Indigenous participants recalled the reserve where she grew up.

The nature, the bush, the trees, freshwater; that is the ideal space I'd like to bring and raise my child into. ... It's just what I know, where I grew up, what I experienced. It makes me happy, relaxed, calm. (I6, First Nations)

\section{Relationships interconnected with physical spaces}

For many of the Indigenous participants and one of the racialised non-Indigenous participants, conceptualisations of culturally safe space were inseparable from relationships:

It's almost like [primary midwife] came in and the energy changed in the [hospital] room again, and it was like calm, 'cuz I trusted her'. (I7, First Nations)

[Cultural safety is] pretty much what [the midwives] did, which was like give me enough space. So like, for example, I had a crap ton of visitors, right? And my visitors [laughs] are, you know, sometimes like very Caribbean and like wanna bring you food and tunes and stuff. ... It made all the difference in the world when, you know, my friends came and got me to laugh, and I just basically just was able to relax and, like you said, be myself and like quit freaking out. ... Just the fact that the space was given for me to be myself. Nobody made a big deal and said, 'oh, you can only have this many people in the room'. (N20, Black/Caribbean)

The role of SGMT in the broader community also arose in discussions about culturally safe spaces. For one of the Indigenous participants, being and feeling connected to community was essential:

In the summer I went to a pow wow and while I was there, I saw my midwife and her family. And then I didn't realize, but the [practice receptionist] was actually dancing and he was in regalia, and I didn't recognize him. When I came into the clinic just after the pow wow, he was telling me how he saw me there. So that makes me feel like, you know, being able to go to these Aboriginal events in the city and to see people who I know makes me feel more connected for sure. (I1, First Nations)

SGMT also had varied but generally positive impacts on the non-Indigenous participants' attitudes towards Indigenous peoples. This mainly occurred through passive exposure and was met with varying degrees of reflexivity:

[My experience at the practice] has sort of has piqued my interest [in the Indigenous community] at a low level. (N18, Chinese/European)

[My experience at the practice] made me read about [Indigenous communities] and get curious about it 
more. It's opened my mind towards this community more than before. (N15, Middle Eastern)

I absolutely have an interest [in engaging with the Indigenous community], but I also feel quite the opposite of entitled. In fact, like I shouldn't be given the privilege to know what other people do, especially Aboriginal people [laughs] given our history, the history of the country, the current state of the country. (N19, white/European)

\section{DISCUSSION}

This study found that Indigenous and non-Indigenous midwifery clients conceptualised and experienced cultural safety at SGMT in different ways. While some ideas were shared across groups (ie, the three domains: Relationships and Communication, Sharing Knowledge and Practice, and Culturally Safe Spaces), the more prominent finding was the unique and distinct ways in which the Indigenous participants conceptualised cultural safety. In this discussion, we use a critical and decolonising lens to explore the significance of the Indigenous participants' conceptualisations and their implications for healthcare practice. We then explore the non-Indigenous participants' conceptualisations and their implications-taking care to highlight the parallels that emerged between the Black and Indigenous participants.

\section{Indigenous conceptualisations of cultural safety}

Coming from diverse backgrounds, each Indigenous participant had their own conceptualisations of cultural safety-of what would make them feel comfortable, respected, and able to be themselves. However, there were aspects of cultural safety that were almost exclusively identified by the Indigenous participants. The conceptualisation of cultural safety as having reciprocal kin-based relationships with midwives, access to Indigenous knowledge protocols, and relationships being connected to the space suggests that the Indigenous participants shared a distinct understanding of relationships, knowledge, and space. These conceptualisations resonate with overarching Indigenous social constructs that exist and have always existed across Indigenous communities..$^{51-55}$

For example, the desire to connect with midwives as family for the process of childbearing could align with the Cree and Métis concepts of wahkootowin. Métis elder and scholar Maria Campbell explains wahkootowin, or the 'kinship or the state of being related' (Ermine as cited in $^{54}$ p.5), as follows:

Today it is translated to mean kinship, relationship, and family as in human family. But at one time, from our place it meant the whole of creation. And our teachings taught us that all of creation is related and inter-connected to all things within it. Wahkootowin meant honouring and respecting those relationships. [It was] our stories, songs, ceremonies, and dances that taught us from birth to death our responsibilities and reciprocal obligations to each other. Human to human, human to plants, human to animals, to the water and especially to the earth. And in turn all of creation had responsibilities and reciprocal obligations to us. ${ }^{54}$ (p.6)

For some Indigenous peoples, relocating within networks of kinship like wahkootowin can heal the ruptures of multigenerational family disruption, abuse, and forced displacement from colonialism. However, kinship must be structured in contexts that are rooted in Indigenous knowledge and practice, and aligned with the diverse and specific personal, family and community histories, experiences, and identities present. Here, we recall how important it was for the Indigenous participants to have access to Indigenous knowledge, protocols, ceremonies, and medicines through SGMT-regardless of their pre-existing level of knowledge or desire to use them. It was also expected that the Indigenous midwives would receive and share this knowledge with Indigenous participants. The ability to pass this knowledge to/from future and past generations was powerful and healing for some of the Indigenous participants. Given the rich crossnation traditions of Indigenous midwifery ${ }^{25}$ these findings signal that the roles and expectations of Indigenous midwives as intergenerational knowledge carriers remain alive and well.

Wahkootowin is inclusive of relationships with specific landscapes, waterways, plants, and animals because these are considered kin. Relationships, responsibilities, knowledge systems, and landscapes are foundationally interconnected across the diversities of Indigenous societies, and reflect a grounding of Indigenous ontologies and epistemologies in local ecosystems. ${ }^{567}$ Through this lens, it is not surprising that the Indigenous participants conceptualised relationships and physical spaces in cultural safety as intertwined.

The presence of Indigenous understandings and approaches to childbearing in large urban centres such as Toronto is significant for several reasons. As reported previously, and discussed by the Indigenous participants, cultural expression, and intergenerational knowledge transmission can be daunting in this context. Systemic anti-Indigenous racism in hospitals ${ }^{36}$; intergenerational gaps in Indigenous childbearing and midwifery knowledge linked to deliberate colonial disruption ${ }^{2558}$; the need to balance knowledge sharing with knowledge protection and preservation; and externally imposed politicisations of Indigenous identities ${ }^{596}$ are only some of the challenges many Indigenous peoples living in cities must face. However, this study demonstrates that Indigenous values and social constructs-including the ability and desire to strengthen kinship networks and build relationships with place-have not been lost with urban Indigenous migrations and the urbanisation of traditional Indigenous landscapes. Despite forced relocations and interruptions by colonial powers, Indigenous peoples have a long and well-documented history of adapting to and 
building relationship with places. ${ }^{61}$ The establishment of urban Indigenous Friendship Centres, ${ }^{62}$ the assertion of traditional Indigenous land use in cities, ${ }^{63} 64$ and the growth of vibrant city-based health, social and education spaces such as SGMT are contemporary examples of how this ability to build relationships with physical spaces in ways that are mutually synergistic with the growth and strengthening of human relationships and the continuity of Indigenous knowledge and practice is thriving.

Reflecting on the diverse and resonant ways in which familial and kinship relationships remain foundational to urban Indigenous communities, this study affirms the importance of Indigenous midwifery and the need for culturally safe services in urban areas like Toronto. The Indigenous participants cherished the existence of SGMT and Indigenous midwifery, describing the unique sense of trust, comfort, connection, and shared understandings they could have with Indigenous midwives. The results show that, while non-Indigenous midwives and providers can provide culturally safe care, Indigenous midwives bring a shared understanding and approach that can have uniquely powerful and positive impacts on the health and well-being of Indigenous clients.

This study also highlights the role that Indigenous midwives play in Indigenous resurgence. Indigenous resurgence involves 'recreating the cultural and political flourishment of the past to support the well-being of our contemporary citizens, ${ }^{65}(\mathrm{p} .51)$ and requires a reclaiming of 'the very best practices of our traditional cultures, knowledge systems and lifeways ${ }^{65}$ (p.17-18). Recall that 'culture' is understood broadly through an Indigenous lens. Illuminating the power of Indigenous midwives and the survival of Indigenous understandings of relationships, knowledge, and space, this study offers a glimpse into the Indigenous resurgence that is occurring in Toronto. When healthcare services assert the inherent value of Indigenous infants, parents, families, communities, and ways of life, and ground Indigenous peoples in their own culture and teachings, they are actively rejecting the dispossession of Indigenous peoples and supporting the possibility of new, non-colonial political and social realities through birthing and family building. ${ }^{66-69}$ In other words, when healthcare services are provided in a culturally safe way to Indigenous peoples-whether by an Indigenous or non-Indigenous provider-it is a political act of care in support of Indigenous resurgence.

\section{Non-Indigenous conceptualisations of cultural safety}

As a relatively heterogeneous group, the non-Indigenous participants' conceptualisations of cultural safety varied. Even though further research is needed to better understand these conceptualisations, patterns did emerge that distinguished the white/European participants' conceptualisations from the racialised participants' conceptualisations. One significant finding was the similarities between how the two participants with Black/Caribbean ancestry and the Indigenous participants conceptualised cultural safety. Although the sample size was small, the common experiences of racism in the healthcare system and understandings of cultural safety in relational, kinbased, and community-specific terms are notable; we are reminded of interconnections between Black and Indigenous communities, including historic and current acts of solidarity in the face of anti-Black and anti-Indigenous racism. These important relationships warrant further attention and exploration and present an opportunity to better understand intersections between Indigenous and Black constructions of cultural safety outside the confines of white colonial configurations. ${ }^{70}$

While cultural safety may not have been specifically designed for white/European clients, this study shows that the Indigenous concept of culturally safe care resonated with and benefited participants with white/European ancestry. For example, several non-Indigenous participants, many of whom were white, spoke to how SGMT itself, given its Indigenous focus and commitment to cultural safety, motivated them to think more broadly about their own cultural needs and identities and in some cases learn more about Indigenous communities. Because dominant Canadian understandings of 'culture' are still narrowly equated with 'racialised communities, ${ }^{, 17}$ it is promising that being asked by midwives to reflect on culture and tradition and actively exposed to Indigenous peoples and Indigenous spaces can help shift thinking.

With regard to white/European participants' conceptualisations of cultural safety, common themes emerged. In general, cultural safety was conceptualised as relationships, knowledge, and spaces that were client-centred and anti-oppressive. The notion that culturally safe care stood in juxtaposition to the highly medicalised, hospitalised, cisheteronormative, physician-dominated, and maledominated mainstream model of perinatal care that has been critiqued elsewhere ${ }^{71} 72$ was widely shared. Themes related to control over choices and spaces were especially prevalent. On reflection, it appears that white participants conceptualised cultural safety in ways that were resonant and at times identical to the core principles in the Ontario midwifery model of care (ie, informed choice, continuity of care and choice of birthplace $\left.{ }^{27}\right)$. While it is likely that all participants valued these principles (hence their choice of a midwife), the white participants were more precise in their articulations of culturally safe care meaning Ontario midwifery care. This finding is significant because it suggests that Ontario midwives are well positioned, by virtue of their philosophy, approach, and model of care, to provide what is considered to be culturally safe care to clients who are white/European. It also raises critical questions about whose understandings of midwifery and culturally safe care are taken into consideration when designing and delivering Ontario midwifery care. For example, the concept of client-centred care and 'getting to know the individual' may not foster cultural safety for Indigenous and racialised clients who understand relationships, knowledge, and space as interconnected manifestations of family, kinship-based societies. Here, we are reminded of the necessity of increasing the 
number of Indigenous and racialised midwives and perinatal care providers and the need to ensure that cultural safety standards, initiatives, and appraisal become a core part of health service functioning and health service provider training. This in turn must draw on understandings of cultural safety that are meaningful and relevant to Indigenous and racialised peoples.

\section{LIMITATIONS}

This study involved a single midwifery practice with a unique focus. Additional research is needed to better understand the relevance of these findings across different midwifery practice contexts. Furthermore, while we attempted to optimise diversity across our sample, participants tended to be older, more educated, and have more hospital births than the average SGMT client. Non-Indigenous participants were also more commonly white. This may be the result of older, more educated, white women being more likely to volunteer for the study and to choose or require hospital births or midwifery care compared with clients who were younger, had less education, and/or who were racialised. We also did not have any Inuit participants, which may be reflective of the small number of Inuit clients at SGMT. We acknowledge that this study is very community-specific and hope it will motivate further exploration of the ways Indigenous and non-Indigenous communities conceptualise and experience culturally safe care across diverse gender identities, sexualities, family situations, income levels, locations, and abilities.

\section{CONCLUSION}

In this study, we interviewed former clients of an urban Indigenous-focused midwifery practice to determine how Indigenous and non-Indigenous clients conceptualised cultural safety, and the extent to which their experiences at the practice aligned with these conceptualisations. Three core domains of cultural safety emerged: Relationships and Communication; Sharing Knowledge and Practice; and Culturally Safe Spaces. Several themes were identified in each domain, with some shared across Indigenous and/or non-Indigenous racialised and/or nonIndigenous white/European groups and some distinct to Indigenous participants. Indigenous participants' unique conceptualisations of cultural safety reflected long-standing Indigenous understandings of relationships, knowledge, and space. The survival of Indigenous values and approaches to childbearing affirms the value of Indigenous midwives, the need for culturally safe care in urban centres, and the resilience and resurgence of urban Indigenous communities.

Assessing cultural safety from the perspective of clients, this study offers new insights to the emerging fields of Indigenous midwifery and cultural safety research. Our results illuminate the unique needs of Indigenous clients, the resilience and resurgence of Indigenous communities in Toronto, and the vital role of Indigenous midwives. We have also demonstrated the positive impacts that culturally safe care can have for clients of all backgrounds. These findings highlight the desire of midwifery clients to see an expansion of Indigenous midwifery services and culturally safe services in urban spaces and beyond and the need to include 'cultural safety' as an indicator in future evaluations of healthcare services and organisations. Making cultural safety the standard of care is a key first step towards interrupting the harms of anti-Indigenous racism and oppression in healthcare, and supporting families and communities to not only be healthy and well, but to thrive.

\section{Author affiliations}

${ }^{1}$ Well Living House, MAP Centre for Urban Health Solutions (C-UHS), St Michael's Hospital, Toronto, Ontario, Canada

${ }^{2}$ Dalla Lana School of Public Health, University of Toronto, Toronto, Ontario, Canada

${ }^{3}$ Seventh Generation Midwives Toronto (SGMT), Toronto, Ontario, Canada

${ }^{4}$ Department of Health Sciences, Lakehead University, Thunder Bay, Ontario, Canada ${ }^{5}$ MAP Centre for Urban Health Solutions (C-UHS), St. Michael's Hospital, Toronto, Ontario, Canada

Acknowledgements We honor and acknowledge the clients from SGMT who so generously shared their time and experiences with us to make this study possible. We would also like to thank the midwives at SGMT for their continued guidance and partnership; Shannon Simpson for assisting with the analysis; and Conrad Prince for supporting the study's design, operations, and management.

Contributors The evaluation within which this study was nested was codeveloped by midwives at Seventh Generation Midwives Toronto (SHW, CB, Sadie Booth, Alanna Kibbe) in partnership with research staff at the Well Living House (JKS (principal investigator), MF, Conrad Prince, Marcie Snyder, Bernice Downey). The evaluation was co-led by SHW and CB in partnership with JKS, MF, and CP. The interview guide for this study was developed by SHW, CB, JKS, MF, and CP with minor comments from MEC and HM. The interviews were conducted and transcribed by MEC as a part of her Master's thesis. The transcripts were analysed by MEC, JKS, and Shannon Simpson, with themes and linked quotes being confirmed on an iterative basis in partnership with SHW and CB. MEC, JKS, and SHW shared the role as primary author for this manuscript, receiving minor edits from CB, HM, and MF. All authors read and approved the final manuscript.

Funding This study was nested within a larger evaluation study that was supported by a grant from the Ontario Ministry of Health and Long-Term Care.

Competing interests None declared.

Patient consent for publication Not required.

Ethics approval This project has been reviewed and approved by the research ethics board of St. Michael's Hospital (REB no: 14-050).

Provenance and peer review Not commissioned; externally peer reviewed.

Data availability statement No data are available. As per the Research Agreement and the principles of OCAP, the data that support the findings of this study (ie, interviews) are owned by Seventh Generation Midwives Toronto. To protect participant privacy and confidentiality, the transcripts are not publicly available. The study interview guide is included in online supplemental appendix A.

Open access This is an open access article distributed in accordance with the Creative Commons Attribution Non Commercial (CC BY-NC 4.0) license, which permits others to distribute, remix, adapt, build upon this work non-commercially, and license their derivative works on different terms, provided the original work is properly cited, appropriate credit is given, any changes made indicated, and the use is non-commercial. See: http://creativecommons.org/licenses/by-nc/4.0/.

ORCID iD

Mackenzie E Churchill http://orcid.org/0000-0003-1313-5214 


\section{REFERENCES}

1 McCallum MJL. Starvation, experimentation, segregation, and trauma: words for reading Indigenous health history. Can Hist Rev 2017;98:96-113.

2 Browne AJ, Smye VL, Rodney P, et al. Access to primary care from the perspective of Aboriginal patients at an urban emergency department. Qual Health Res 2011;21:333-48.

3 Goodman A, Fleming K, Markwick N, et al. "They treated me like crap and I know it was because I was Native": The healthcare experiences of Aboriginal peoples living in Vancouver's inner city. Soc Sci Med 2017;178:87-94.

4 Hanrahan MC. Identifying the needs of Innu and Inuit patients in urban health settings in Newfoundland and Labrador. Can J Public Health 2002;93:149-52.

5 Monchalin R, Smylie J, Nowgesic E. "I guess I shouldn't come back here": racism and discrimination as a barrier to accessing health and social services for urban Métis women in Toronto, Canada. J Racial Ethn Health Disparities 2020;7:251-61.

6 Allan BSJ. First peoples, second class treatment: the role of racism in the health and well-being of Indigenous peoples in Canada. Toronto, ON: Well Living House and St. Michael's Hospital, 2015.

7 Brian Sinclair Working Group. Out of sight: interim report of the Brian Sinclair Working group. Winnipeg, MB: Brian Sinclair Working Group, 2017.

8 Denison J, Varcoe C, Browne AJ. Aboriginal women's experiences of accessing health care when state apprehension of children is being threatened. J Adv Nurs 2014;70:1105-16.

9 Kurtz DLM, Nyberg JC, Van Den Tillaart S, et al. Silencing of voice: an act of structural violence urban Aboriginal women speak out about their experiences with health care. Int $\mathrm{J}$ Indig Health 2013;4:53.

10 Nestel S. Colour coded health care: the impact of race and racism on Canadians' health. Toronto: Wellesley Institute, 2012

11 Human Rights and Health Equity Office, Sinai Health System. Black experiences in health care: symposium report. Toronto, ON: Sinai Health System, 2017: 15.

12 Curtis E, Jones R, Tipene-Leach D, et al. Why cultural safety rather than cultural competency is required to achieve health equity: a literature review and recommended definition. Int $J$ Equity Health 2019;18:174.

13 Ramsden IM. Cultural safety and nursing education in Aotearoa and te Waipounamu. Wellington, New Zealand: University of Wellington, 2002: 223.

14 Browne AJ, Varcoe C. Critical cultural perspectives and health care involving Aboriginal peoples. Contemp Nurse 2006;22:155-68.

15 Browne AJ, Varcoe C, Smye V, et al. Cultural safety and the challenges of translating critically oriented knowledge in practice. Nurs Philos 2009;10:167-79.

16 Diffey L, Lavallee B. Is cultural safety enough? Confronting racism to address inequities in Indigenous health. OEFD News 2016;2:2-5.

17 Brascoupé S. Exploring the applicability of the concept of cultural safety to Aboriginal health and community wellness. Int J Indig Health 2009;37.

18 Gerlach AJ. A critical reflection on the concept of cultural safety. Can J Occup Ther 2012;79:151-8.

19 Wood PJ, Schwass M. Cultural safety: a framework for changing attitudes. Nurs Prax N Z 1993;8:4-15.

20 Baba L. Cultural safety in first nations, Inuit and Métis public health Prince George: National Collaborating Centre for Aboriginal Health, 2013: 44 .

21 Ward C, Branch C, Fridkin A. What is Indigenous cultural safety and why should I care about it? Visions 2016;11.

22 Anderson J, Perry J, Blue C, et al. "Rewriting" cultural safety within the postcolonial and postnational feminist project: toward new epistemologies of healing. ANS Adv Nurs Sci 2003;26:196-214.

23 Riggs E, Muyeen S, Brown S, et al. Cultural safety and belonging for refugee background women attending group pregnancy care: an Australian qualitative study. Birth 2017;44:145-52.

24 National Aboriginal Council of Midwives. Working with NACM: values, responsibilities and ways to work together. National Aboriginal Council of Midwives, 2019.

25 Caroll D, Benoit C. Aboriginal midwifery in Canada: Merging traditional practices and modern science. In: Bourgeault IL, Benoit C Davis-Floyd R, eds. Reconceiving midwifery. Quebec City: McGillQueens University Press, 2004: 263-86.

26 Association of Ontario Midwives. What is a midwife? 2020. Available: https://www.ontariomidwives.ca/what-midwife [Accessed 27 Jun 2020].

27 Association of Ontario Midwives. Midwifery care, 2020. Available: https://www.ontariomidwives.ca/midwifery-care [Accessed 27 Jun 2020].
28 Association of Ontario Midwives. Mission, vision, values, 2020. Available: https://www.ontariomidwives.ca/mission-vision-values [Accessed 27 Jun 2020]

29 Brown AE, Middleton PF, Fereday JA, et al. Cultural safety and midwifery care for Aboriginal women - A phenomenological study. Women Birth 2016;29:196-202.

30 Kruske S, Kildea S, Barclay L. Cultural safety and maternity care for Aboriginal and Torres Strait Islander Australians. Women Birth 2006;19:73-7.

31 Phiri J, Dietsch E, Bonner A. Cultural safety and its importance for Australian midwifery practice. Collegian 2010;17:105-11.

32 Olson R, Couchie C. Returning birth: the politics of midwifery implementation on first nations reserves in Canada. Midwifery 2013;29:981-7.

33 Van Wagner V, Epoo B, Nastapoka J, et al. Reclaiming birth, health, and community: midwifery in the Inuit villages of Nunavik, Canada. $J$ Midwifery Womens Health 2007;52:384-91.

34 Seventh Generation Midwives Toronto. SGMT - about, 2020. Available: https://www.sgmt.ca/about [Accessed 27 Jun 2020]

35 Statistics Canada. Toronto [Census metropolitan area], Ontario and Ontario [Province] (table). 2016 Census. Statistics Canada catalogue no. 98-316-X201600, 2017. Available: https://www12.statcan.gc.ca/ census-recensement/2016/dp-pd/prof/index.cfm?Lang=E [Accessed 27 Jun 2020].

36 Rotondi MA, O'Campo P, O'Brien K, et al. Our health counts Toronto: using respondent-driven sampling to unmask census undercounts of an urban Indigenous population in Toronto, Canada. BMJ Open 2017;7:e018936.

37 Seventh Generation Midwives Toronto. Statement on Indigenous identity. Seventh Generation Midwives Toronto, 2017.

38 Kishk Anaquot Health Research. Community guide to evaluating Aboriginal healing Foundation activity, 2001. Available: http://www. ahf.ca/downloads/community-guide.pdf [Accessed 27 Jun 2020].

39 Patton MQ. Utilization-focused evaluation. 4th ed. London: Sage Publications, 2008.

40 Pawson R, Tilley N. Realistic evaluation. London: Sage, 1997.

41 Firestone M, Smylie J, Maracle S, et al. Unmasking health determinants and health outcomes for urban first nations using respondent-driven sampling. BMJ Open 2014;4:e004978.

42 Smylie J. Knowledge translation and Indigenous communities: A decolonizing perspective. In: Banister E, Leadbeater B, Marshall $\mathrm{E}$, eds. Knowledge translation in context: Indigenous, policy, and community settings. Toronto: University of Toronto Press, 2011: 181-200.

43 Smylie J, Kaplan-Myrth N, et al, Métis Nation of Ontario-Ottawa Council, Pikwakanagan First Nation, Tungasuvvingat Inuit Family Resource Centre. Indigenous knowledge translation: baseline findings in a qualitative study of the pathways of health knowledge in three Indigenous communities in Canada. Health Promot Pract 2009;10:436-46.

44 Smylie J, O'Brien K, et al, De dwa da dehs nye>s Aboriginal Health Centre. Primary care intervention to address cardiovascular disease medication health literacy among Indigenous peoples: Canadian results of a pre-post-design study. Can J Public Health 2018;109:117-27.

45 Canadian Institutes of Health Research, Natural Sciences and Engineering Research Council of Canada, Social Sciences and Humanities Research Council of Canada. Chapter 9: Research involving the First Nations, Inuit and Métis peoples of Canada. In: Tri-Council policy statement (TCPS) 2: ethical conduct for research involving humans. Ottawa: Her Majesty the Queen in Right of Canada, 2018

46 Smylie J, Firestone M. Back to the basics: identifying and addressing underlying challenges in achieving high quality and relevant health statistics for Indigenous populations in Canada. Stat J IAOS 2015;31:67-87.

47 Tongco MDC. Purposive sampling as a tool for informant selection. Ethnobot Res Appl 2007;5:147-58.

48 Carlson JA. Avoiding traps in member checking. Qual Rep 2010;15:1102-13.

49 Green J, Thorogood N. In-depth interviews. In: Qualitative methods for health research. London: SAGE Publications, Inc., 2014: 95-125.

50 Crabtree BF, Miller WL. The dance of interpretation. In: Doing qualitative research. Thousand Oaks: SAGE Publications, 1999: 127-43.

51 Anderson K. Life stages and native women: memory, teachings, and story medicine. 15. Winnipeg, MB: University of Manitoba Press, 2011

52 Flaminio AL. Gladue through wahkotowin: social history through Cree kinship lens in corrections and parole, 2013. 
53 Macdougall B. Land, family and identity: Contextualizing Métis health and well-being. Prince George: National Collaborating Centre for Aboriginal Health, 2017: 32.

54 MacDougall B. Wahkootowin : Family and cultural identity in northwestern Saskatchewan Métis communities. Can Hist Rev 2006;87:431-62.

55 Little Bear L. Jagged worldviews colliding. In: Battiste MA, ed. Reclaiming Indigenous voice and vision. Vancouver: UBC Press, 2000: 77-85.

56 Basso KH. Wisdom sits in places: landscape and language among the Western Apache. Albuquerque: University of New Mexico Press, 1996.

57 Henderson JY. Ayukpachi: Empowering Aboriginal thought. In: Battiste MA, ed. Reclaiming Indigenous voice and vision. Vancouver: UBC Press, 2000: 248-78.

58 Lawford K, Giles A. Marginalization and coercion: Canada's evacuation policy for pregnant First Nations women who live on reserves in rural and remote regions. Pimatisiwin: A Journal of Aboriginal and Indigenous Community Health 2012;10:327-40.

59 Lawrence B. "Real" Indians and others: Mixed-blood urban Native peoples and indigenous nationhood. Vancouver: UBC Press, 2004.

60 Richardson C. Métis identity creation and tactical responses to oppression and racism. Variegations 2006;2:56-71.

61 De Costa R. Cosmology, mobility and exchange: Indigenous diplomacies before the nation-state. Can Foreign Policy $J$ 2007:13:13-28

62 National Association of Friendship Centres. About the NAFC, 2020. Available: https://www.nafc.ca/en/about-the-nafc [Accessed 27 Jun 2020].
63 Native Canadian Centre of Toronto. First story Toronto app \& bus tour, 2020. Available: https://ncct.on.ca/programs/first-story-torontoapp-bus-tour/ [Accessed 27 Jun 2020].

64 Ogimaa Mikana Project. Ogimaa mikana: reclaiming/renaming, 2020. Available: https://ogimaamikana.tumblr.com/ [Accessed 27 Jun 2020].

65 Simpson L. Dancing on our turtle's back: stories of Nishnaabeg recreation, resurgence and a new emergence. Winnipeg, MB: Arbeiter Ring Pub, 2011.

66 Coulthard GS. Red skin, white masks: rejecting the colonial politics of recognition. University of Minnesota Press, 2014.

67 Corntassel J. Re-envisioning resurgence: Indigenous pathways to decolonization and sustainable self-determination. Decolonization: Indigeneity, Education \& Society 2012;1:86-101.

68 Simpson A. The state is a man: Theresa Spence, Loretta Saunders and the gender of settler sovereignty. Theory \& Event 2016;19.

69 Tabobondung R, Wolfe S, Smylie J, et al. Indigenous midwifery as an expression of sovereignty. In: Lavell-Harvard D, Anderson K, eds. Mothers of the nations: Indigenous mothering as global resistance, reclaiming and recovery. Bradford: Demeter Press, 2014: 71-88.

70 Tuck E, Walcott R. A conversation between Eve Tuck and Rinaldo Walcot. Available: http://www.thehenceforward.com/episodes/2017/ 5/17/episode-13-a-conversation-between-dr-eve-tuck-dr-rinaldowalcott

71 Shaw JCA. The medicalization of birth and midwifery as resistance. Health Care Women Int 2013;34:522-36.

72 Parry DC. "We wanted a birth experience, not a medical experience": exploring Canadian women's use of midwifery. Health Care Women Int 2008:29:784-806. 